\title{
FLUOROQUINOLONAS X RESISTÊNCIA BACTERIANA NA MEDICINA VETERINÁRIA
}

\author{
J.M.B. da Silva; C.B. Hollenbach
}

Universidade Federal do Rio Grande do Sul, Departamento de Farmacologia, Instituto de Ciências Básicas da Saúde, Av. Sarmento Leite, 500, CEP 90046-900, Porto Alegre, RS, Brasil. E-mail: gatilmaktub@gmail.com

RESUMO

As fluoroquinolonas são um grupo de substâncias químicas sintéticas com atividade antimicrobiana, com extensiva aplicação tanto na medicina humana como também na medicina veterinária, consideradas importantes armas no combate a organismos Gram-negativos, Grampositivos e as últimas gerações destes agentes antimicrobianos chegam a ser ativas contra as bactérias anaeróbias. Atualmente é uma das maiores classes de agentes antimicrobianos sendo utilizadas, mundialmente, no tratamento de infecções de origem bacteriana. As suas indicações terapêuticas evoluíram da aplicação em infecções urinárias a aplicações nas mais variadas infecções. Este grupo de fármacos foi se desenvolvendo de forma a ultrapassar grande parte das suas adversidades, possuindo hoje um espectro de ação bastante abrangente, boa disponibilidade oral, melhor difusão para os tecidos, uma meia vida maior e uma toxicidade consideravelmente reduzida. Esta revisão reúne informações atuais sobre as propriedades físico-químicas, farmacocinética, metabolismos de ação e de resistência das fluoroquinolonas de uso veterinário.

PALAVRAS-CHAVE: Fluoroquinolonas, antimicrobianos, resistência bacteriana.

\section{ABSTRACT}

FLUOROQUINOLONES X BACTERIAL RESISTANCE ON VETERINARY MEDICINE. The fluoroquinolones are a group of synthetic chemicals with antimicrobial activity. They have extensive application in human medicine and also in veterinary medicine, are considered important weapons in fighting Gram-negative and Gram-positive microorganism, and the latest generation of these antimicrobial agents is also active against the anaerobic bacteria. Nowadays it is one of the largest classes of antimicrobial agents globally in use to treat bacterial infections. Its therapeutic indications developed from application in urinary infections to nearly all infections in the body. This group of drugs has been developed in order to overcome most of its adversities, having nowadays, a larger spectrum of action, good oral availability and better dissemination to the tissues, increased half-life and toxicity considerably reduced This review brings together current information about the physical-chemical properties, pharmacokinetics and metabolism of action and resistance of fluoroquinolones for veterinary use.

KEY WORDS: Fluoroquinolone, antimicrobial, bacterial resistance.

\section{Descrição farmacológica}

As quinolonas surgiram, acidentalmente, como produto secundário da síntese de um agente antimalárico, de atividade antibacteriana conhecida e comprovada, a cloroquina. A substância foi descoberta no ano de 1962 por George Lesher e colaboradoresem uma destilação, durantea síntese decloroquina. No entanto, este produto secundário revelou possuir também atividade antimicrobiana, surgindo assim a primeira quinolona: o Ácido Nalidíxico (ANDRIOLE, 2000; Higgins et al., 2003).

O ácido nalidíxico foi a primeira quinolona a ser introduzida, seguindo-se a flumequina e o ácido oxonílico, sendo então denominadas quinolonas de primeira geração. Este grupo tornou-se de escolha no combate às doenças urinárias de difícil tratamento, devido a eficiência contra a maioria das Enterobacteriaceae. No entanto, nenhum destes compostos possuía qualquer atividade contra Pseudomonas, anaeróbios e bactérias Gram-positivas. Na década de 1980, após intensas pesquisas realizadas a partir destas primeiras quinolonas, originaram as denominadas quinolonas de segunda geração, as fluoroquinolonas (APPELBAUM; HUNTER, 2000).

Quimicamente, as fluoroquinolonas diferem das anteriores por possuírem a combinação de um átomo de flúor e um grupo piperazinil. As principais representantes deste grupo são a enrofloxacina (uso exclusivo em medicina veterinária), norfloxacina, 
ciprofloxacina, ofloxacina, lomefloxacina e a perfloxacina. Esta combinação levou a um maior espectro de ação, a um aumento da capacidade das quinolonas penetrarem na parede bacteriana levando, consequentemente, a uma melhor atividade contra bactérias Gram-negativas, passando a abranger algumas espécies Gram-positivas e atingiu um perfil farmacocinético melhor, chegando a ter uma atividade antibacteriana 1.000 vezes superior à observada pelo ácido nalidíxico, seu antecessor (SOUSA, 2007). Existe, atualmente, um grande número de novas fluoroquinolonas e as modificações estruturais efetuadas permitiram que esta classe de antimicrobiano se desenvolvesse significativamente, desde os primeiros compostos sintetizados até aos novos compostos, cujo maior espectro de ação e farmacocinética permite uma única dosagem diária (SouZA, 2005).

As fluoroquinolonas, como já descrito acima, pertencem a uma classe de agentes antimicrobianos com um largo espectro de atividade contra organismos Gram-positivoseGram-negativos, assim como microorganismos anaeróbios, sendo a sua ação terapêutica fundamental, sobretudo em infecções causadas por micro-organismos resistentes a outras classes de fármacos (SouZA, 2005).

Deste modo, as propriedades físico-químicas das quinolonas vão influenciar o comportamento destas tanto in vivo como in vitro, especialmente as suas propriedadesácido/base, capacidadepara complexar íons metálicos, assim como o seu caráter hidro/ lipofílico (PARK, 2002). É importante salientar que a atividade antimicrobiana das quinolonas depende basicamente do $\mathrm{pH}$ do meio em que se encontram, visto atuarem por inibição da DNA girase (enzima alvo destes fármacos) e esteéum processo quedepende do pH e concentração de ácido (SÁRKÖZY, 2001).

A presença de um grupo ácido (grupo carboxílico) e de um grupo básico (amina terciária) atribui ao composto propriedades anfotéricas podendo, deste modo, existir mais do que uma espécie presente em solução, dependendo do $\mathrm{pH}$, devido à protonação/desprotonação destes grupos influenciando, assim, o comportamento farmacológico destes compostos, uma vez que a presença de grupos carregados é necessária para a atividade biológica (PARK et al, 2002). Dependendo do $\mathrm{pH}$ em que se encontra o meio, as quinolonas podem existir sob as formas catiônica, aniônica, neutra ou de íon dipolar. O pH 7,4 (fisiológico) das quinolonas encontra-se total ou parcialmente ionizados, sendo a espécie predominante a forma de íon dipolar podendo, no entanto, coexistir com as formas aniônica e catiônica (PARK et al., 2000).

Sousa (2007) relatou as constantes de acidez de duas fluoroquinolonas; na enrofloxacina, é possível verificar que o $\mathrm{pH} 7,4$ encontra-se $92 \%$ na forma deíon dipolar, $4 \%$ na forma aniônica e $4 \%$ na forma catiônica. No entanto, a ciprofloxacina, que difere apenas da enrofloxacina pela presença de umátomo dehidrogênio no anel piperazínico, já se encontra $90 \%$ na forma de íon dipolar e 10\% na forma aniônica.

Deacordocom as constantes deacideze diferentes estruturas, as quinolonas vão exibir diferentes ações antibacterianas. Sendo as porinas uma das principais vias de entrada das quinolonas nas células bacterianas Gram-negativas, a hidrofobicidade, o peso molecular, e a forma iônica em pH fisiológico são propriedades que vão complicar a interação destes fármacos. Nocaso das bactérias Gram-positivas, como estas não possuem uma membrana externa, onde se encontram os canais porínicos, a difusão através da membrana celular será o local de entrada dos antibióticos na célula bacteriana e, neste caso, a hidrofobicidade do compostoé a propriedade maisimportante (SousA, 2007).

No que se refere à farmacocinética das fluoroquinolonas, após a administração por via oral (principal via de administração), estes antimicrobianos são rapidamente absorvidos por animais monogástricos e pré-ruminantes. Por outro lado, o pico máximo de concentração sérica varia conforme a espécie animal; assim, por exemplo, após a administração oral de enrofloxacina, esta fluoroquinolona atinge o pico máximo de concentração sérica $0,5,0,9$, 1,4,2,4, e5,4horas, respectivamente, em equinos, cães, perus, galinhas e bovinos. Uma das principais vantagens do uso das fluoroquinolonas é o seu largo volume de distribuição, além da baixa ligação com as proteínas plasmáticas (ANDRADE et al., 2002).

FRAZIER et al. (2000), compararam os parâmetros farmacocinéticos da marbofloxacina, enrofloxacina (incluindo se metabólito ativo a ciprofloxacina) e a difloxacina em cães, utilizando amostras de pele, plasma e urina. Os autores relatam que a concentração plasmática versus a curva de tempo da marbofloxacina foi maior do que comparada aos valores da enrofloxacina, ciprofloxacina, enrofloxacina/ ciprofloxacina combinadas, e difloxacina. A concentração máxima da marbofloxacina foi maior do que a enrofloxacina, ciprofloxacina e difloxacina. O tempo da concentração plasmática foi semelhante para marbofloxacina e difloxacina,já para a enrofloxacina/ ciprofloxacino ocorreram mais cedo e mais tarde, respectivamente. $\mathrm{Na}$ análise do plasma, a meia-vida da marbofloxacina foi mais demorada do que para enrofloxacina, ciprofloxacina e difloxacina. Os resultados das amostras de pele ena concentração na urina foram semelhantes, onde a difloxacina mostrou valores inferiores, a enrofloxacina e a marbofloxacina/ ciprofloxacina combinadas obtiveram os mesmos valores. 
Existe grande controvérsia sobre o uso das fluoroquinolonas em pacientes pediátricos devido aos seus efeitos adversos sobre as cartilagens dos ossos longos (Plumb, 2004). Há relatos de artropatias por erosãona cartilagem articular, em animais jovens de crescimento rápido, sendo contra indicado o uso em gatos, cães de pequeno e médio porte, nos primeiros 8 meses de vida e em cães de raças grandes e gigantes durante os primeiros 18 meses de vida (ANDRADE et al., 2002). MARTí (2005) descreveu que as fluoroquinolonas não seriam o fármaco de primeira escolha para tratamento de filhotes septicêmicos devido ao seu baixo espectro contra algumas espécies de estreptococos e bactérias anaeróbicas.

Estudos relatam casos de cegueira em gatos por degeneração retiniana após tratamento com enrofloxacina relacionados as doses superiores a 5 $\mathrm{mg} / \mathrm{kg}$ a cada 24 horas. Atualmente, recomenda-se $2,5 \mathrm{mg} / \mathrm{kg}$ de $12 / 12 \mathrm{~h}$ e também que seja evitada a via intravenosa. No cão não foi relatado tal efeito, mantendo sua dose padrão (WIEBE; HaMilton, 2002).

BiANCIARDiet al. (2004) testaram a eficácia do uso de Enrofloxacina, no tratamento da Leishmaniose. Os autores sugerem que o fármaco in vitro não possui atividade direta contra o parasito, mas queé capaz de induzir um aumento da produção de óxido nítrico pelos macrófagos. In vivo, demonstraram que ocorre uma melhora no quadro clínico dos cães tratados, principalmente nas lesões de pele. Sugerem então, que este fármaco apresenta, neste caso, atividade imunomoduladora e poderia ser associado a uma droga leishmanicida como um novo protocolo de tratamento para Leishmaniose.

Recentemente, Vouldoukis et al. (2006) avaliaram a eficácia in vitro da Marbofloxacina, fluoroquinolona de terceira geração, contra formas promastigotas de Leishmania infantum. Os autores sugerem que este fármaco pode vir a se tornar uma alternativa promissora no tratamento da Leishmaniose quando associado a outras drogas leishmanicidas, por ser relativamente barato, debaixa toxicidadee administrado por via oral.

Preocupados com as escassas informações a respeito da farmacocinética da enrofloxacina em lhamas, Himelfarb et al. (2007) realizaram uma pesquisa baseada na evolução dos níveis séricos em duas diferentes vias deadministração. A administraçãointramuscular emlhamas $(\mathrm{N}=6)$ foi homogênea, os autores observaram uma rápida absorção durante a primeira hora, a Cmax foi alcançada em 2-3h. As concentrações se encontraram acima de $1 \mathrm{mg} / \mathrm{mL}$ durante mais de $10 \mathrm{~h}$ e os níveis se mantiveram acima do limite de quantificação até as $12 \mathrm{~h}$. Já na administração subcutânea foram observadas variações individuas dentro do grupo testado. A Cmax foi alcançada em 90 minutos. As concentrações permaneceram acima de $1 \mathrm{mg} /$ $\mathrm{kg}$ durante mais de $12 \mathrm{~h}$ e os níveis se mantiveram acima do limite de quantificação até $24 \mathrm{~h}$. Com relação ao metabólito ativo, a ciprofloxacina mostrou níveis baixos em comparação a outras espécies mamíferas herbívoras.

SCHOLAR (2002) descreve que as fluoroquinolonas atuam por inibição da atividade catalítica de duas enzimas responsáveis e essenciais à replicação e transcrição do DNA bacteriano: a DNA girase e a topoisomerase IV (topoisomerases dotipo II). Comenta ainda que na sua forma relaxada, o DNA existe como uma dupla hélice que pode ser enrolada e torcida no sentido contrário levando a um super enrolamento da dupla hélice. Para que haja replicação é necessário que as duas cadeias se separem, ou seja, quea dupla hélicesedesenrole. Ograu deenrolamento do DNA depende da ação combinada super enrolamento/relaxamento das duas enzimas.

A DNA girase é responsável pelo super enrolamentonegativo enquanto que a topoisomerase IV o remove, promovendo o relaxamento da molécula do DNA. Uma vez que ambas as enzimas são essenciais ao crescimento e divisão das células bacterianas, aobloquearem a ação destas enzimas inibem todos os processos consequentes da sua ação levando, assim, à morte da célula bacteriana (FelLI, 2007).

NACHAMKIN et al. (2002) investigaram a resistência à quinilona de Campylobacterjejuni, queéa causa mais comum de gastroenterite bacteriana nos Estados Unidos. Esta infecção entérica é essencialmente uma doença de origem alimentar, onde as aves domésticas são as principais fontes de infecção. $O$ estudo foi realizado entre os pacientes do sistema de saúde na Pensilvânia, no período ente 1982 a 2001, revelando que não se observou fluoroquinolona resistente ao $C$. jejuni entre 1982-1992, no entanto, a resistência aumentou para 40,5\% em 2001.

Também nos Estados Unidos, McDermott et al. (2002) pesquisaram os efeitos da sarafloxacina e enrofloxacina no tratamento de frangos infectados com C. jejuni, no desenvolvimento de resistência. Quando a sarafloxacina ou enrofloxacina foram utlizadas com doses aprovadas pela FDA - EUA em frangos de corte, a resistência se desenvolveu rapidamente e persistiu em $C$. jejuni. Os resultados desta pesquisa concluem que essa resistência de Campilobacter pode resultar em terapia fluoroquinolona menos eficaz para os casos de campilobacteriose humana adquirida por exposição a frangos contaminados.

Embora as infecções causadas por sorotipos nãotifoides de Salmonella enteritidis e S. typhi causarem sintomas bastante diferentes, os mecanismos de resistência das fluoroquinilonas são semelhantes ao todo, se isoladas de animais, alimentos ou humanos. A Salmonella contendo uma única mutação em GyrA, 
ao mesmo tempo tornar-se resistente ao ácido nalidíxico e diminuiu susceptibilidade da flouroquinolona e os MICs são geralmente inferiores aos das concentrações recomendadas desses agentes na maioria dos países (PIDDOCK, 2002). No entanto, foram documentadas falhas da terapia, sugerindo que o uso de uma fluoroquinolona para tratar uma infecção causada por um ácido nalidíxico resistente a $S$. typhimurium pode muito bem não ser efetivo (PiDDOCK et al., 1993).

Na Tailândia, CHIU et al. (2002) investigaram o rápido aparecimento de resistência à fluoroquinilona pela Salmonella enterica sorotipo choleraesuis, em suínos. Esta investigação indicou que o sorotipo choleraesuis, em suínos resistentes à fluoroquinolona, pode se espalhar de suínos para o homem. Os autores sugerem, inclusive, que utilização a de fluoroquinolonas em alimentos para animais deveria ser proibida.

Os mecanismos de resistência desenvolvidos por bactérias à ação antibacteriana das quinolonas ocorrem por dois mecanismos fundamentais:

1 - Alterações nas moléculas alvo: as enzimas DNA girase e topoisomerase IV;

2 - Alterações a nível da acumulação intracelular dos antibióticos.

Um acúmulo intracelular reduzido pode ser devido a uma diminuição da permeabilidade da membrana externa do fármaco pelo fato das proteínas membranares (porinas) sofrerem alterações que afetam a sua expressão ou pela estimulação dos sistemas de efluxo celular que leva à expulsão do fármaco, da célula, por transporte ativo (VAN BAMBEKE et al., 2005).

Devido ao uso abusivo das quinolonas e os relatos de resistência bacteriana fez-se necessária a produção de novas estruturas que possuíssem um espectro de ação maior e, então, atuassem nas cepas resistentes. Estas alterações estruturais, provavelmente, influenciam as propriedades físico-químicas dos antibióticos que, por sua vez estão relacionadas com a maior atividade antibacteriana das quinolonas mais recentes (SOUSA, 2007).

Ao contrário das quinolonas de primeira geração, a administração clínica das fluoroquinolonas produz mutantes resistentes numa frequência ainda bastante pequena (NARDELLI, 2008).

YAMASHITA et al. (2005) realizaram o isolamento e caracterização de Staphylococci, em especial o Staphilicoccus schleiferi subsp. coagulans. As amostras foram coletadas do meato auditivo externo de cães com ou sem otite externa. Oresultado sobrea resistência da bactéria em questão frente à ação da norfloxacina, ofloxacina e ciprofloxacina não foi significativo, alcançando de 3,1\% para 9,4\%. Comprovando que a resistência dessas fluorquinolonas, frente às infecções auditivas por Staphilicoccus schleiferi subsp. coagulans, é rara em cães.

Em gatosjá foi comprovada significativa resistência da enrofloxacina para tratamento de Pseudomodas sp. (POMBA-FérIA et al., 2002).

CAstagna et al. (2001) observaram amostras de Salmonella sp. em suínos após o abate e constataram que o grupo das quinolonas (ciprofloxacina e ácido nalidíxico), apesar do uso crescente em suinocultura, não apresentou níveis de resistência elevados.

Ribeiro; FilHo (1999) examinaram 29 amostras de Rhodococcus equi isoladas de afecções pulmonares em potros, realizaram oteste de sensibilidade microbiana pelo método de difusão em discos, frente a 26 antimicrobianos. Os resultados referentes às fluoroquinolonas foram: enrofloxacina (35,5\% Sensível, $45,2 \%$ sensibilidade intermediária e 19,3\% resistente) e ciprofloxacina ( $64,5 \%$ Sensível, $32,3 \%$ sensibilidade intermediária e 3,2\% resistente) mostrando que ambas são eficazes no tratamento das afecções pulmonares em potros.

Num estudo mais completo realizado por CoHNet al. (2003), durante os anos de 1992 até 2001, através do isolamento bacteriano do trato urinário de cães, onde objetivaram observar a tendência do aumento da resistência bacteriana frente as fluoroquinolonas. As espécies predominantes no isolamento bacterial foram: Escherichia coli, Proteus mirabilis, Staphylococcus intermedius, e como representante das fluoroquinolonas utilizaram ora enrofloxacina ora ciprofloxacina. Os autores constataram um aumento proporcional e significativo no aumento da resistência bacteriana frente às fluoroquinolonas testadas durante os anos do experimento.

No experimento de SASAKI et al. (2007), onde os objetivos eram determinar e comparar a suscetibilidade in vitro da enrofloxacina sobre 94 Pseudomonas aeroginosa isoladas de camundongos tratados e não tratados com enrofloxacina, e também em 40 Pasteurella pneumotropica, para avaliar a eficácia e os efeitos da enrofloxacina no tratamento em animais de laboratório. Os resultados de suscetibilidade indicaram a P. pneumotropica como superior em comparação com a $P$. aeroginosa, e que o tratamento com enrofloxacina possivelmente não influencia a suscetibilidade da P. aeroginosa.

A Organização Mundial de Saúde relata as mesmas recomendações referentes ao uso das fluoroquinolonas e quinolonas para uso em animais. Dentre estas:

1 - as quinolonas, como qualquer agente antibiótico, nunca devem ser usadas como substituto das boas práticas de manejo de animais;

2 - as quinolonas devem ser administradas de acordo com práticas que maximizem o efeito terapêutico e minimize o risco de resistência, as quais incluem:

a) tratamentos efetuados somente com supervisão do 
veterinário ou em animais sob seus cuidados e com registros escritos de uso;

b) tratamentos baseados em diagnósticos laboratoriais, sempre que seja possível, em cultivos bacterianos e testes de susceptibilidade, mantendo registro destes testes nos estabelecimentos;

c) quando os resultados do cultivo e da susceptibilidade bacteriana são conhecidos, é preferível um antibiótico eficaz de espectro reduzido antes que uma quinolona.

3 - O registro de quinolonas deveria ser só para uso terapêutico e não para aumentar o rendimento (crescimento), deveriam ser registradas somente para prescrição farmacêutica veterinária, com apropriada observância dessa exigência.

4 - Deveria ser descartada a utilização de quinolonas em animais produtores de alimentos nas indicações além das permitidas. (World Health Organization, 1998).

\section{Considerações finais}

Dentro da União Europeia o número de antibióticos disponíveis para uso clínico aumentou de cinco antibióticos em 1959, para cento e duas moléculas diferentes em 1997. O uso intensivo de um maior número de substâncias e a diversificação das suas aplicações (para além da terapêutica), aumentaram inexoravelmente o "pool" de genes de resistência em bactérias patogênicas, zoonóticas e comensais. De fato, a dispersão emergente de genes que expressam mecanismos de resistência às drogas com proprieda- des antibióticas, bem como a seleção denovas estirpes microbianas antibiorresistentes, coincidiu somente com o uso generalizado de antibióticos (COSTA et al., 2001).

Costa (2002), relatou que, em escala mundial, estimava-se em 27.000 toneladas a quantidade de antibióticos usados em saúde animal. Destes, 25\% foram usados dentro da União Europeia, sendo 50\% destinados a fins terapêuticos, $25 \%$ incorporados na alimentação com o objetivo de promover ocrescimento, e $25 \%$ usados na prevenção da coccidiose em frangos e perus de carne, como aditivos alimentares ionóforos. Para Portugal, estimou-se que a quantidade de promotores de crescimento comercializados durante o ano de 1997, foi de 24 toneladas.

$\mathrm{O}$ uso de medicamentos veterinários na fase de terminação do frango de corte foi investigado pelo ProgramaEstadual deControle de Resíduos de Medicamentos Veterinários em Alimentos de Origem Animal (PAMvet-PR) no Estado do Paraná, uma vez que deteminados antimicrobianos poderiam deixar resíduos na carne. Com referência aos grupos farmacológicos mais utilizados com a função preventiva na fase de desenvolvimento final da produção do frangodecorte(Fig. 1), foram: fluoroquinolonas (34\%); ionóforos (20\%); macrolídeos (10\%), as quinolonas e tetraciclinas $(6 \%)$, sulfonamidas $(4 \%)$ e as lincosamidas (3\%). E, utilizados como terapêuticos, observou-se a citação dos ionóforos (25\%); das fluoroquinolonas (19\%); sulfonamidas (14\%); tetraciclinas (11\%); â lactâmicos (7\%), macrolídeos (5\%) e aminoglicosídeos (4\%) (Fig. 2)

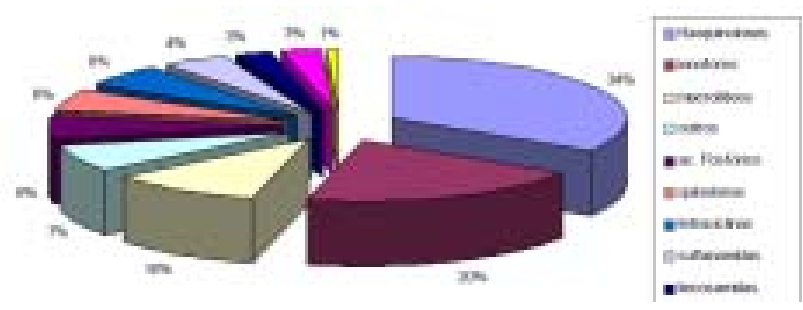

Fig. 1- Grupos farmacológicos mais utilizados com a função de prevenção na fase final da produção de frango de corte. Fonte: PAMvet-PR.

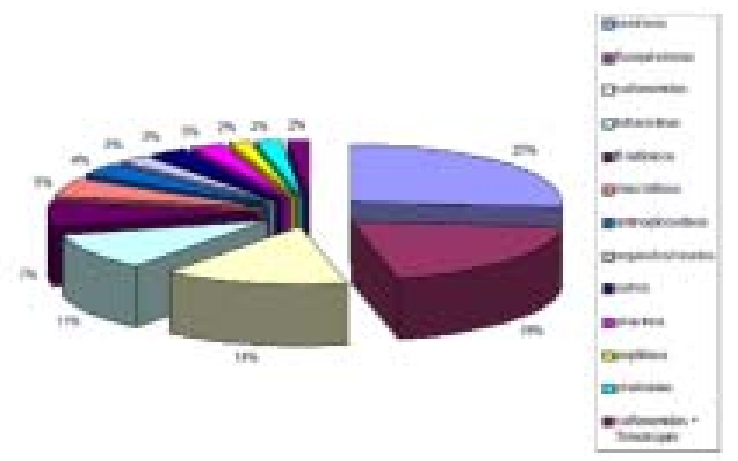

Fig. 2 - Grupos farmacológicos mais utilizados com a função terapêutica na fase final da produção de frango de corte. Fonte: PAMvet-PR. 
As fluoroquinolonas se caracterizam por uma boa atividade antimicrobiana, inclusive contra micro-organismos poucos susceptíveis ou resistentes. Têm um excelente comportamento farmacocinético, com fácil administração, são poucos os dados de interação com outros fármacos, permitindo seu uso concomitante com outros medicamentos sem riscos aumentando assim seu índice terapêutico, possui boa absorção e uma distribuição tissular que garante uma concentração mínima inibitória frente à maioria dos micro-organismos causadores das enfermidades dos animais.

Estes fármacos representam, sem dúvida, uma excelente ferramenta para o manejo clínico na medicina veterinária. No entanto dados de resistência microbiana justificam o cumprimento das recomendações da Organização Mundial de Saúde para o uso seguro destes antimicrobianos.

\section{REFERÊNCIAS}

ANDRADE, S.F.; GIUFFRIDA, R.; RIBEIRO, M.G. Quimioterápicos, antimicrobianos e antibióticos. In: ANDRADE S.F. (Ed.). Manual de terapêutica veterinária. São Paulo: Roca, 2002. p.13-58.

ANDRIOLE, V.T. The Quinolones. 3.ed. Maryland Haights: Elsevier, 2000.

\section{APPELBAUM, P.C.; HUNTER, P.A. The}

fluoroquinolone antibacterials: past, present and future perspectives. International Journal of Antimicrobial Agents, v.16, p.5-15, 2000.

BIANCIARDI, P.; FASANELLA, A.; MANZILLO, V.F.; TROTTA, T.; PAGANO, A.,S ORINO, S.; GRADONI, L.; OLIVA, G. The efficacy of enrofloxacin, alone or combined with metronidazole, in the therapy of canine leishmaniasis. Parasitology Research, v.93, n.6, p.486-492, 2004.

CASTAGNA, S.M.F.; BESSA, M.C.; CARVALHO, D.A.; CARDOSO, M.; COSTA, M. Resistência a antimicrobianos de amostras de Salmonella sp. isoladas de suínos abatidos no estado do Rio Grande do Sul. Arquivos da Faculdade de Veterinaria, UFRGS, v.29, p.4449, 2001.

CHIU, C-H.; WU, T-L.; SU, L-H.; CHU, C.; CHIA, J-H.; KUO, A-J.; CHIEN, M-S.; LIN, T-Y. The emergence in Taiwan of fluoroquinilone resistance in Salmonella enterica serotype Choleraesuis. New England Journal of Medicine, v.346, n.6, 2002.

COHN, L.A.; GARY, A.T.; FALES, W.H.; MADSEN, R.W. Trends in fluoroquinolone resistance of bacteria isolated from canine urinary tracts. Journal of Veterinary Diagnostic Investigation, v.15, p.338-343, 2003.
COSTA, P.M. Resistance to antibacterians in poultry. In: VETERINARY SCIENCES CONGRESS, 2002, Oeiras. Proceedings. Oeiras, 2002. p.251-260

COSTA, P.M.; SILVA, D.M.; MIRANDA, J. Ensaio de campo com a vacina Paracox 5 em frangos criados em regime extensivo, 2001.

FELLI, V. M.A. Quinolonas Antibacterianas. São Paulo: Faculdade de Ciências Farmaceuticas, USP, 2007. 15p. [Apostila - Química Farmacêutica I] Disponível em: <http:/ /www.fcf.usp.br/Ensino/Graduação/Disciplinas/ Exclusivo/Inserir/Anexos/LinkAnexos/QUINILONA>.

FRAZIER, D.L.; THOMPSON, L.; TRETTIEN, A.; EVANS, E.I. Comparison of fluoroquinolone pharmacokinetic parameters after treatment with marbofloxacin, enrofloxacin, and difloxacin in dogs. Journal of Veterinary Pharmacology and Therapeutics, p.293-302, 2000.

HIGGINS, P.G.; FLUIT, A.C.; SCHMITZ, F.J. Fluoroquinolones: structure and target sites. Current Drug Targets, v.4, p.181-189, 2003.

HIMELFARB, M.; LANGRE, R.; SONIA Y DAER, M. Evolución de los niveles séricos de enrofloxacina y su metabolito activo, ciprofloxacina, tras administración intramuscular y subcutánea en llamas. Revista Complutonse de Ciencias Veterinárias, v.1, n.2, p468-474, 2007.

MARTÍ, S. Farmacologia e terapêutica pediátrica. In: PRATS, A. neonatologia e pediatria canina e felina. São Paulo: Interbook, 2005. p.270-289.

McDERMOTT, P.F.; BODEIS, S.M.; ENGLISH, L.L.; WHITE, D.G.; WALKER, R.D.; ZHAO, S.; SIMJEE, S.; WAGNER, D.D. Ciprofloxacin resistance in Campylobacter jejuni evolves rapidly in chickens treated with fluoroquinolones. Journal of InfectiousDeseases, v.185, p.837-840, 2002.

NACHAMKIN, I.; UNG, H.; LI, M. Increasing fluoroquinolone resistance in Campylobacter jejuni, Pennsylvania,USA,1982-2001. Emerging Infectious Diseases, v.8, n.12, p.1501-1503, 2002.

NARDELLI, R. Quimioterápicos. Disponível em: <http:/ / ynardelli.wordpress.com/>. Acesso em: 12 out. 2008.

PAMvet-PR/ 2005 - Levantamento do uso e comercialização de medicamentos veterinários em frango de corte. Disponível em: <http:/ /www.saude. pr.gov.br/arquivos/File/vigilancia \%20sanitaria/ Relatorio\%20levantamento\%20frango.pdf>. Acesso em: 12 out. 2008.

PARK, H.R.; CHUNG, K.Y.; LEE, H.C.; LEE, J.K.; BARK, K.M. Ionization and divalent cation complexation of quinolone antibiotics in aqueous solution. Bulletin of the Korean Chemical Society, v.21, n.9, p.849-854, 2000. 
PARK, H.R.; KIM, T.H.; BARK, K.M. Physicochemical properties of quinolone antibiotics in various environments. European Journal of Medicinal Chemistry, v.37, p.443-460, 2002.

PIDDOCK, L.J.V. Fluoroquinolone resistance in Salmonella serovars isolated from humans and food animals. FEMS Microbiology Reviews, v.26, p.3-16, 2002.

PIDDOCK, L.J.V.; GRIGGS, D.J.; HALL, M.C.; JIN, Y.F. Ciprofoxacin-resistance in clinical isolates Salmonella typhimurium obtained from two patients. Antimicrobial Agents and Chemotherary, v.37, p.662-666, 1993.

PLUMB, D.C. Drugs in neonates: principles and guesses. In: ANNUAL CONFERENCE OF THE SOCIETY FOR THERIOGENOLOGY, 2004, Lexington, Kentucky. Proceedings. Lexinxgton: 2004. p.307-314.

POMBA-FÉRIA, C.; COSTA, M.; CANIÇA, M.; CORREIA, J. D. In vitro activity of enrofloxacin, marbofloxacin and ciprofloxacin against clinical strains of Pseudomonas spp. isolated from small animals on Portugal. In: WORLD SMALL ANIMAL VETERINARY ASSOCIATION, 27., 2002, Dublin, Irland. Proceedings. Dublin, 2002.

RIBEIRO, M.G.; FILHO, A.S.C. Afecções pulmonares em potros. Saúde Eqüina, v.2, n.13, 1999.

SCHOLAR, E. M. Fluoroquinolines: Past, present and future of a novel group of antibacterial agents. American Journal of Pharmaceutical Education, v. 66, p.164172, 2002.

SÁRKÖZY, G. Quinolones: a class of antimicrobial agents. Veterinarni Medicina, v.46, n.9/10, p.257-274, 2001.

SASAKI, H.; KAWAMOTO, E.; KUNITA, S.; YAGAMI, $\mathrm{K}$. Comparison of the in vitro susceptibility of rodent isolates of Pseudomonas aeruginosa and Pasteurella pneumotropica to enrofloxacina. Journal of Veterinary Diagnostic Investigation, v.19, p.557-560, 2007.
SOUSA, I.C. Interacção da Enrofloxacina com modelos biomembranares: influência das suas propriedades físicoquímicas. 2007. Dissertação (Mestrado em Tecnologia, Ciência e Segurança Alimentar) - Faculdade de Ciências da Universidade do Porto, Lisboa, Portugal, 2007.

SOUZA, M.V.N. New fluoroquinolones: A class of potent antibiotics. Minireviews in Medicinal Chemistry, v.5, p.1019-1017, 2005.

VAN BAMBEKE, F.; MICHOT, J. M.; VAN ELDERE, J.; TULKENS, P. M. Quinolones in 2005: an update. Clinical Microbiology and Infection, v.11, p.256-280, 2005.

VOULDOUKIS, I.; ROUGIER, S.; DUGAS, B.; PINO, P.; MAZIER, D.; \& WOEHRLÉ, F. Canine visceral leishmaniasis: Comparison of in vitro leishmanicidal activity of marbofloxacin, meglumine antimoniate and sodium stibogluconate. Veterinary Parasitology, v.135, n.2, p.137-146, 2006.

WIEBE, V.; HAMILTONA, P. fluoroquinoloneinduced retinal degeneration in cats. Journal of the American Medical Association, v.221, p.1568-1571, 2002.

WORLD HEALTH ORGANIZATION. Use of quinolones in food animals and potential impact on human health. In: Report and proceedings of a WHO meeting, Geneva, Switzerland, 2-5 June 1998. Disponível em: <http://whqlibdoc.who.int/hq/1998/ WHO_EMC_ZDI_98.12_(p1-p130).pdf>. Acesso em: 12 out. 2008.

YAMASHITA, K.; SHIMIZU, A.; KAWANO, J.; UCHIDA, E.; HARUNA, A.; IGIMI, S. Isolation and characterization of Staphylococci from external auditory meatus of dogs with or without otitis externa whit special reference to Staphilicoccus schleiferi subsp. coagulans isolates. Journal of Veterinary Medicine Science, v.67, n.3, p.263-268, 2005.

Recebido em 5/11/08

Aceito em 19/11/09 
